\title{
The evil lies below the surface: Subsquamous tumor extension in Barrett's adenocarcinoma
}

Author

Institution

\author{
Werner Dolak
}

Medical University of Vienna, Internal Medicine III., Division of Gastroenterology and Hepatology
Bibliography

Dol http://dx.doi.org/

10.1055/s-0034-1365450

Endoscopy International Open

2014; 02: E41-E42

(c) Georg Thieme Verlag KG

Stuttgart $\cdot$ New York

E-ISSN 2196-9736

\section{Corresponding author}

Werner Dolak

Medical University of Vienna Internal Medicine III., Division of Gastroenterology and Hepatology

Waehringer Guertel 18-20

1090 Vienna

Austria

Fax: 0043-1-40400-4735

werner.dolak@meduniwien.ac. at
The presence of intestinal metaplasia underneath the surrounding squamous epithelium is a well known phenomenon in Barrett's esophagus (BE) [1]. Mostly caused by re-epithelialization with neosquamous epithelium in the context of mucosal healing (due to acid suppressive therapy or after biopsy sampling, for example), this issue has recently attracted new attention in the context of an increasing application of ablative therapies for Barrett's esophagus, above all radiofrequency ablation (RFA). Although follow-up studies after RFA treatment have shown that the frequency of so called "buried glands" after re-epithelialization with neosquamous epithelium is much lower than previously feared, the limited diagnostic accessibility of these structures below the surface is still worrisome due to their potential risk of malignant transformation [2]

Retrospective studies on resection specimens of Barrett's adenocarcinoma have revealed subsquamous extension of intestinal metaplasia and even neoplasia in a huge number of cases [3]. Although the clinical impact of this "subsquamous tumor extension" (SSTE) is still controversial, it needs consideration in the context of assessing the lateral borders of neoplastic lesions prior to endoscopic resection, especially for carcinomas arising near the squamocolumnar junction. As for buried glands, the prediction of SSTE relying on superficial features is very difficult. Slight elevation and irregular vascular architecture might be some of the subtle changes that can be seen in areas of the squamous epithelium that have been undermined by an adjacent adenocarcinoma. Attempts to improve visualization of SSTE included the use of chromoendoscopy with acetic acid, magnifying endoscopy with narrow band imaging, and optical coherence tomography $[4,5,6]$. However, controlled studies on the additional diagnostic yield of these techniques for the detection of SSTE are still lacking.
Given that SSTE is mostly limited to a few millimeters, this raises the question whether it is really necessary to assess its precise extent in order to achieve complete resection of neoplasia. In the present study of Nagamy et al. which represents a retrospective analysis of prospectively gained clinical data, the authors investigated the efficacy of endoscopic submucosal dissection (ESD) on tumors of the esophagogastric junction (EGJ). Applying a proximal safety margin of $1 \mathrm{~cm}$ outside of the squamocolumnar junction or the slight elevation interpreted as SSTE, they were able to achieve an en bloc resection rate of $100 \%$ for both gastric cardia carcinoma and Barrett's adenocarcinoma. For the latter, the histological evaluation revealed SSTE in 12/14 cases, half of them undetected prior to endoscopic resection, but at worst $7 \mathrm{~mm}$ at maximum extent, wherefore the authors concluded quite rightly that a safety margin of $1 \mathrm{~cm}$ may be acceptable for ESD in these tumors.

Although exact delineation of SSTE by advanced endoscopic imaging techniques may be fancy, the study by Nagamy et al. nicely demonstrates that a simple and clear algorithm for resection margins based on former clinical experience may lead to excellent results for endoscopic resection. Even if SSTE might be frequent and sometimes indiscernible, it seems to be a soluble problem in the endoscopic management of Barrett's adenocarcinoma.

Competing interests: None 


\section{References}

1 Sharma P, Morales TG, Bhattacharyya A et al. Squamous islands in Barrett's esophagus: what lies underneath? Am J Gastroenterol 1998; 93: $332-335$

2 Gray NA, Odze RD, Spechler SJ. Buried metaplasia after endoscopic ablation of Barrett's esophagus: a systematic review. Am J Gastroenterol 2011; 106: 1899-1908

3 Anders M, Lucks Y, El-Masry MA et al. Subsquamous Extension of Intestinal Metaplasia Is Detected in 98\% of Cases of Neoplastic Barrett's Esophagus. Clin Gastroenterol Hepatol 2014; 12: 405 - 410

4 Yamagata T, Hirasawa D, Fujita $N$ et al. Efficacy of acetic acid-spraying method in diagnosing extension of Barrett's cancer under the squamous epithelium. Dig Endosc 2012; 24: 309-314

5 Omae M, Fujisaki J, Shimizu T et al. Magnifying endoscopy with narrow-band imaging findings in the diagnosis of Barrett's esophageal adenocarcinoma spreading below squamous epithelium. Dig Endosc 2013; $25: 162-167$

6 Cobb MJ, Hwang JH, Upton MP. Imaging of subsquamous Barrett's epithelium with ultrahigh-resolution optical coherence tomography: a histologic correlation study. Gastrointest Endosc 2010; 71: 223-230 